\title{
Airport baggage handling - where do human factors fit in the challenges that airports put on a baggage system?
}

\author{
O.N.M. Lenior* \\ Systems Concepting, Vanderlande Industries B.V.,Vanderlandelaan 2, 1013 BG, Veghel, The Netherlands
}

\begin{abstract}
The challenges put on large baggage systems by airports can be summarized as: handling a high number of bags in a short period of time, in a limited space, with all sorts of disruptions, whilst complying with stringent regulation upon security, sustainability and health and safety. The aim of this company case study is to show in the different project phases - as indicated in the system ergonomic approach - how the human factors specialist can play a major part in tackling these challenges. By describing different projects in terms of scope, organization, human factors topics covered, phases and lessons learned, the importance of Human-Computer Interaction, automation as well as manual handling and work organization in baggage is addressed.
\end{abstract}

Keywords: System ergonomics, HF engineering, Human-Computer Interaction, manual handling, work organization

\section{Introduction}

Looking at an airport baggage system from a passengers' perspective, it is quite often seen as a conveyor on which the passenger drops his bag. Subsequently that bag is screened and transported to an output point of the baggage system, loaded into a loading unit (LU) and taken to the aircraft. After the flight the passenger collects his bag at the arrival destination. See figure 1.

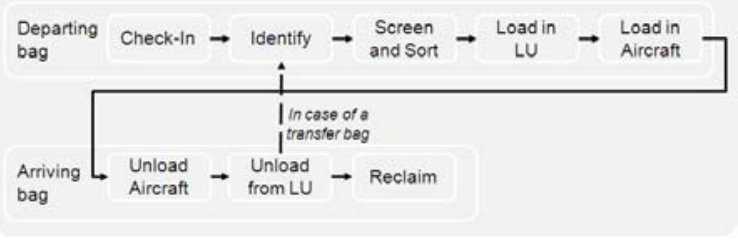

Figure 1: Baggage process

The process does not appear to be complex. However, especially for the large airports it is quite a chal- lenging operation. Besides being faced with overall high passenger/bag numbers and with the usual disruptions in the process, also the peaks in bag flows and time constraints are challenging. Passengers desire short connection times to transfer onto another flight. Airports also need to comply with more stringent regulation upon security processes, sustainability (reduced energy consumption) and health and safety (less or no manual handling). Furthermore space in the existing terminal buildings is of great value, which means that severe space restrictions are set for baggage systems. All together it becomes clear that quite some challenges are put on baggage system suppliers.

Vanderlande Industries B.V. is a supplier of baggage systems to airports ${ }^{\mathrm{i}}$. In the past that mainly implied delivering transport conveyors (mechanics); nowadays the controls (IT) of these transport systems is at least as important. In fact Vanderlande integrates products of several software and hardware suppliers to deliver a total baggage solution.

\footnotetext{
EE-mail: odeke.lenior@vanderlande.com
} 
This company case study sketches a couple of projects of Vanderlande and the most remarkable aspects of the ergonomic contributions. These projects, all on major European airports, vary from relatively small (i.e. approximately 5 million euro and completion in less than 1.5 year) to very large projects ( $\sim 350$ million euro, completion time of 6 years).

The experience has learned that no two airports are the same, no two buildings identical, no two business cases alike and therefore each system design and each project is unique. However, the baggage projects do have in common the group of main stakeholders, their different interests and the interplay of forces between these stakeholders.

The main users of the baggage system are the airlines and their handlers. However, for the large European baggage projects it is important to recognize that the airport is the main customer of the baggage system integrator. These supplier-customer relationships for the main stakeholders are indicated in figure 2.

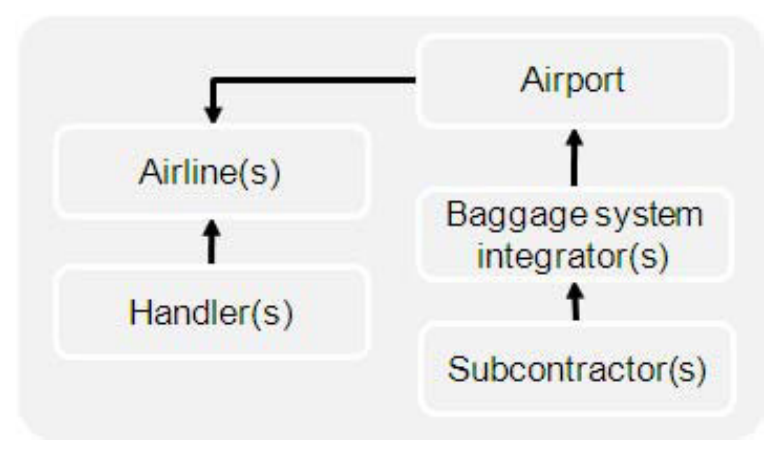

Figure 2: Supplier-customer relationships for main stakeholders

Ergonomics often only play a modest part in the total project, although the last couple of years it is noticed that the Health and Safety regulations are more stringently being followed; mainly for the physical ergonomics. Moreover management recognizes that human factors are a key factor in effectivity and efficiency. In the successive projects described hereafter, it can be seen that there is an increasing opportunity to follow a structured, systems ergonomic approach as described by Pikaar [1], incl. references to ISO-EN Safety of Machinery norms with design process and risk assessment steps.

The main stakeholders more and more have their own human factors specialists involved; during as well as after project delivery, when auditing the result. The human factors specialist employed with Vanderlande, being closest to the design and engineering of the baggage system, is best able to constructively influence the concepts, applications and workplaces.

In the first project described in this paper, I was hired as a cognitive ergonomist, because it was clear that controls/IT had become an important part of the baggage system. At the IEA 2006 congress I presented the main issues and lessons learned (Lenior [2]).

Over the years it appeared that in the highly automated systems, still the physical impossibilities of the active human operator seem to be the bottleneck. In chapter 3 and 4 of this paper options are shown to tackle these.

\section{Cognitive ergonomics in a baggage project}

\subsection{Project scope}

For one of the world's busiest airports a completely new baggage system has been designed and implemented. A system crossing 6 floors in a $400 \mathrm{~m}$ long building; starting at the top where check-in is located down to the basements where a bag store for early bags as well as a connection via a tunnel to a second building ${ }^{1}$ has been realized.

A system that is capable of sorting 12.000 bags per hour, with daily interaction in the field of approximately 300 users/operators, split over 15 different types of roles, i.e. 15 different types of workplaces. And a baggage control room where 6 different types of roles need to monitor and control the baggage system and the processes. For all these roles and workplaces different software applications needed to be designed, developed, tested and users needed to be trained.

\subsection{Project organization}

Within Vanderlande, the project team underneath the project management was split in an overall system architects team and 10 to 15 (depending on the project phase) mechanical and software component teams. The full time human factors specialist was initially part of the system architects team, at a later stage part of the change control board and integration team and - at the end of the project - part of the commissioning and operational readiness/go live team.

\footnotetext{
${ }^{1}$ Note that the system still is being expanded. It is planned to have five buildings connected by 2015 .
} 


\subsection{Human factors topics covered}

The main human factors topics covered in this project were those that also required a lot of user participation:

- Situation analysis

* incl. observations and interviews

- Task/function analysis and task allocation

* see Lenior [2] and Kirwan [3]

- User Interaction design

* incl. prototyping workshops affiliation(s)

- User training

\subsection{Project phases}

The global system design had already taken place by the time the human factors specialist joined the system architects team. However, the incremental development and long completion time allowed for an ergonomic contribution in all phases.

\section{Step 1 \& 2. Feasibility and problem definition}

Some software applications were new developments, others were re-used applications of earlier projects. Especially the 're-use applications' that were delivered by a subcontractor, were evaluated and (partly) adapted to the foreseen user tasks and roles.

\section{Step 3. Analysis}

A situation analysis of the operation at other terminals has taken place as well as an hierarchical task/ function analysis of the future situation. Also task allocation took place at this stage. For some stakeholders it appeared to be difficult to commit to a certain way of working.

\section{Step 4. Functional design}

The task analysis formed the basis of the User Interaction (UI) design of the different (software) components and very much helped in the decision making.

\section{Step 5. Detailed engineering}

Prototyping with the users in this step was essential to get the details of the applications right. However still some decisions upon role-definitions were lacking, which implied that 'all options needed to be kept open', unfortunately resulting in a non-optimal UI. Another reason for non-optimal UI's was the fact that some applications were 're-use applications' and contractually only had limited options for adaptation.

\section{Step 6. Implementation}

During the implementation phase the human factors specialist was also part of the test team, i.e. doing usability tests.

\section{Step 7. Commissioning}

In this phase training materials were jointly developed by the human factors specialist with a training specialist as well as with trainers of the stakeholders who would provide the training to their end users.

\section{Step 8. Evaluation}

The period before as well as after going live, the human factors specialist - part of the operational readiness team - was in the control room to coach the control room operators. This not only helped the operators, but also the human factors specialist in really experiencing and learning what was good and mainly: what could still be improved in all the applications.

\subsection{Lessons learned}

The main lessons learned are:

- Task- and function analysis is essential in driving the design, it enables better and quicker decision making in the Human-Computer Interaction design;

- Having a project-wide style guide ready before the software component teams even start UI design, will save a lot of time consuming discussions;

- It is very hard to get truly consistent and usable user interaction over different applications, when these are developed in different technologies by different teams and subcontractors;

- Being part of the system architects team and of a change control board that is back upped by project management is essential to be able to steer the design;

- Putting more intelligence in the baggage system, i.e. have the system determine the alternative routes that a bag travels in case of disruptions, 
improves the overall figures for bags reaching their flights on time. For operators in the control room it is however essential to be aware of the routing decisions taken by the system and to be able to overrule;

- Ensure that budgets are reserved and an organization is in place for changes to the systems after go live. Advanced understanding by the users of how the system exactly works will - especially in the first year of operation - result in quite some enhancement requests.

\section{A semi-automated loading project}

\subsection{Project scope}

This baggage project needs to deliver a system that automatically transports bags via a tunnel (approx. $500 \mathrm{~m}$ long) from one terminal building to another. This task is currently done manually, i.e. loading bags from the output point of one baggage system into a van, then driving them to another terminal and unloading them onto the input conveyors. The new system allows baggage to be automatically transported from one terminal to another terminal; at peaks this can encompass 3000 bags per hour.

\subsection{Project organization}

In this project the humans factors specialist was pulled in when the scope changed halfway the project. The process for transporting bags from one terminal to the second terminal would be fully automated, but the process for transferring bags to a $3^{\text {rd }}$ and $4^{\text {th }}$ terminal would still remain a van driving process. This implied that manually lifting of bags for those terminals would still be needed. Due to a further developed manual handling strategy at the airport the scope of the project was changed; manual handling of these bags was not allowed anymore and Vanderlande was asked to find alternative solutions for the layout of the baggage system in the limited building space available.

\subsection{Human Factors topics covered}

The main task for the human factors specialist was to evaluate semi-automated loading devices specifically for this van-loading task. Semi-automated loading (see figure 3) implies that devices are installed at output points of the baggage system onto which bags are automatically loaded, such that the operator only needs to position the device in the van at the location where he wants the bag to be dropped;

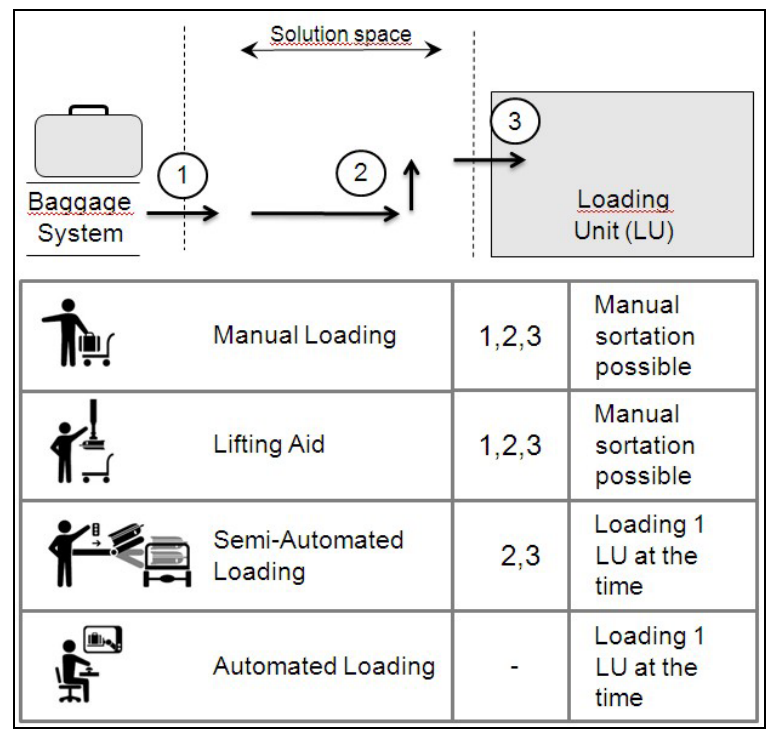

Figure 3: Definitions of different types of loading

Other tasks for the human factors specialist were simulation works and steering and guiding trainers in the development of training material.

\subsection{Project phases}

\section{Step $1 \& 2$. Feasibility and Problem definition}

In this phase the human factors specialist worked with the simulation team to check whether - and under which assumptions - an output plan for only four output points was feasible. Simply because more semi-automated loading devices would not fit in the building. This implied not only checking whether the system could deal with the required peak bag flow, but also whether the workload at each of the output points would be acceptable for the van driver. The desired system capacity could still be achieved when an operator could load approximately 5 times faster with a semi-automated loading device then when he needed to load bags manually.

\section{Step 3. Analysis}

A situation analysis of the manual operation has taken place. Together with an external colleague ergonomist a task-/functional analysis, a NIOSH- and 
an OWAS-analysis have been executed and recommendations for the workplace design have been provided.

\section{Step 4. Functional design}

Several semi-automated loading devices have been evaluated against ergonomic criteria as well as aspects like cost, capacity, maintainability and whether it would fit in the space available. A device has been selected and partially redesigned to make it suitable for this purpose. Also several iterations/redesigns of the baggage system have taken place to ensure that it would all fit in the building.

\section{Step 5. Detailed engineering}

A test set up has been installed with a mock-up van (see figure 4) where usability of the device was tested jointly with the airport and details of the workplace have been sorted out.

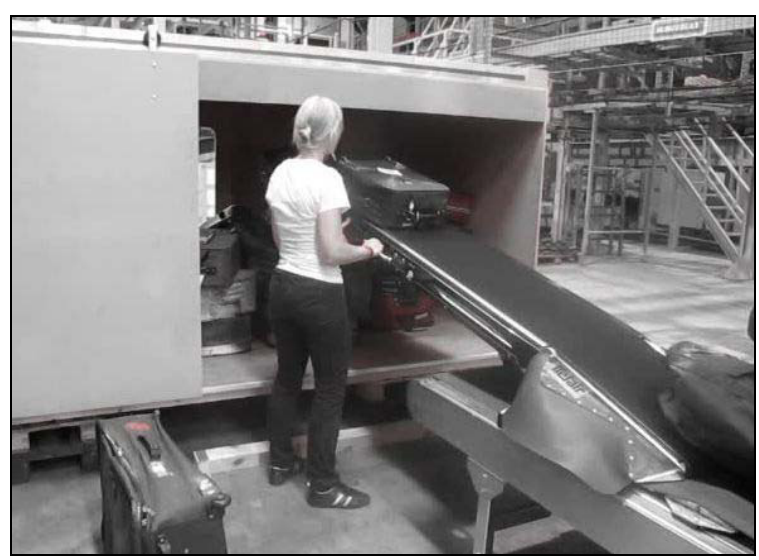

Figure 4: Loading a mock up with a Telair RTT semi-automated loading device.

Step 6, 7 and 8. Implementation, commissioning and evaluation

The implementation and commissioning of the manual handling devices is currently taking place. The human factors specialist checks the workplaces on site and provides guidance to the training development.

\subsection{Lessons learned}

The first main lesson learned is that simulation tools are not only essential to determine whether capacities of the system are sufficient for the required bag flow, but in projects where operator tasks are changing this much, it is also necessary to determine - in the design stage - whether workloads for operators are foreseen to be acceptable.

The second lesson is that designing a completely new workplace and a set of operator tasks halfway through the project, implied that certain aspects (e.g. building limitations and road layouts) could not be changed anymore. This redesign did result in an improved manual handling situation, however at an earlier stage some of the concessions that were made would not have been necessary.

\section{Further reduction of manual handling of baggage}

The two projects described indicate two types of opportunities that improve ergonomics in baggage:

- Smarter controls (IT) and

- More (semi-)automated loading.

In other baggage projects these two aspects are even further developed. Fully automated loading of bags in a loading unit by a robot is already operational at a major airport and will be installed at another. See figure 5 . The human operator monitors the robot doing the loading, only manually intervening when needed. To make this possible, the baggage system has also been designed around this type of operation. Rather than sending a bag to an output point whenever it has been cleared after screening (as was indicated in figure 1) it is now transported to a bag store, that buffers bags until the moment that there are sufficient bags that can exactly fill a loading unit. 


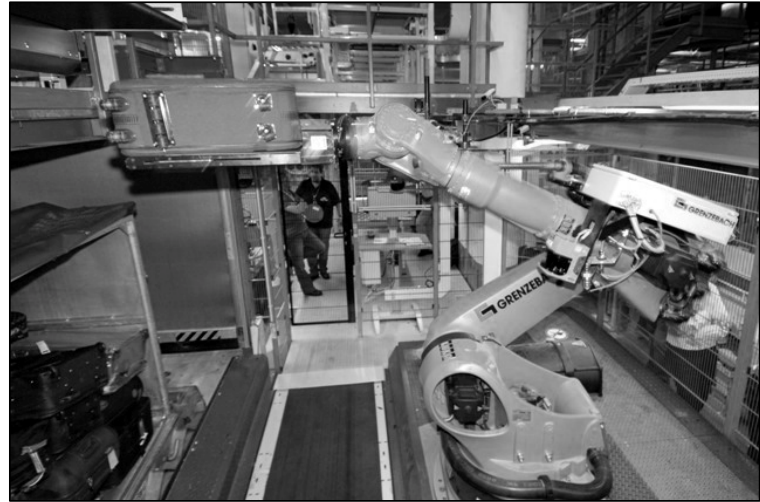

Figure 5: Automated loading of bags (Robot loading)

Also more semi-automated loading is implemented in projects. Again, to make efficient use of the resources (equipment as well as human resources), smarter IT systems are implemented. So, besides the health of the operators (whether or not prompted by legislation), it is mainly a quicker logistic process, less disruptions, higher productivity per operator and less absenteeism that is the motivator for these types of investments. Or, as stated by Dul and Neumann [4]: The cost per unit (i.e. the cost per bag) can be reduced and labour productivity increased.

\section{Conclusions}

The human operator and his physical limitations are still the bottleneck in the overall logistic process. More and more 'human' tasks are automated; in the control room as well as at the (un)loading locations. However fully automated systems are not (yet) a feasible solution for all airports, not only due to cost or space limitations, but also due to required flexibility in operation.

To achieve the desired efficiency, whilst still keeping the required flexibility, it is essential that not only the mechanical and IT products continue to develop, also the users of the baggage system (airports, airlines and their handlers) need to design different operational processes and organization of work.

It can also be concluded that experience on different projects was needed, to show management the added value of early, structured contributions of a human factors specialist.

Actually, the main lesson learned is that potential customers, before they go out to tender, need to have seen the added value of human factors. Because only when these aspects are incorporated as requirements in the tender documents the airport baggage world can grow to a higher level from human factors perspective.

\section{References}

[1] R.N. Pikaar, New Challenges: Ergonomics in Engineering Projects, in: Meeting Diversity in Ergonomics. Proceedings IEA 2006 Congress, Pikaar R.N., Koningsveld, E.A.P., Settels, P.J.M. (eds), Elsevier Ltd., 2007.

[2] O.N.M. Lenior, Human Factors in the control of a Baggage Handling System at an airport - Implementing a revised operational concept. Paper presented on the IEA 2006 Congress.

[3] B. Kirwan and L.K. Ainsworth, A guide to task analysis. Taylor \& Francis Ltd, London, 1992

[4] J. Dul and W.P. Neumann, The strategic business value of ergonomics, in: Meeting Diversity in Ergonomics. Proceedings IEA 2006 Congress, Pikaar R.N., Koningsveld, E.A.P., Settels, P.J.M. (eds), Elsevier Ltd., 2007.

\footnotetext{
${ }^{\mathrm{i}}$ Note that Vanderlande Industries B.V. provides material handling solutions, i.e. besides baggage systems also services, warehouse $\&$ distribution and parcel $\&$ postal systems.
} 